\title{
Identification and Quantification of Boeravinone-B in Whole Plant Extract of Boerhaavia diffusa Linn and in its Polyherbal Formulation
}

\author{
A. Singh ${ }^{*}$, H. Sharma, R. Singh, P. Pant, N. Srikant and K. S. Dhiman \\ Central Council for Research in Ayurvedic Sciences, Janakpuri - 110058, New Delhi, India; \\ arjunccras@gmail.com
}

\begin{abstract}
Objective: To ascertain the authenticity of Boeravinone-B in Boerhaavia diffusa and its poly-herbal dosage form (capsule) by identification and quantification through precise and robust HPLC method. Materials and Methods: The RP-HPLC analysis was accomplished employing phosphate buffer and acetonitrile as mobile phase at a flow rate of $1.5 \mathrm{ml} / \mathrm{min}$ and $270 \mathrm{~nm}$ as detection wavelength. Results: The content of Boeravinone $B$ in ingredients (hydro-alcoholic extracts of whole plant) and poly-herbal formulation of $B$. diffusa was estimated as $0.041 \% \mathrm{w} / \mathrm{w}$ and $0.011 \% \mathrm{w} / \mathrm{w}$, respectively with good linearity R2>0.9997 and retention time $24.413 \pm 0.004 \mathrm{~min}$. Conclusion: The amount of Boeravinone-B present in B.diffusa extracts of raw drug complies with that of reported in literature. Quantification of Boeravinone-B suggested an identification mark for this drug and its different market formulations and may work as quality parameter in standardization. On the basis of percentage of Boeravinone-B the content of $B$.diffusa in poly-herbal formulation validate the ratio of ingredient in final formulation. This method proved its applicability in quality assessment via quantification of this marker in raw material as well as various phyto-formulations of $B$. diffusa and widens the acceptability criteria at international level.
\end{abstract}

Keywords: Boerhaavia diffusa Formulation Analysis, Boerhaavia diffusa Whole Plant Extract, Boeravinone-B Quantification, HPLC of Boerhaavia diffusa

\section{Introduction}

Due to the lack of scientific validity, the Ayurvedic and classical medicines have poor acceptability in world market. The acceptance of their formulations at global level highly needs evidence-based advancements of Ayurvedic research ${ }^{1}$. Now there is an urgent necessity to validate raw drugs as ingredients and various polyherbal formulations through incorporation of advanced techniques. In view of this, HPLC is precise, robust

${ }^{*}$ Author for correspondence

Email: snehabherji@gmail.com analytical technique for estimation of major bioactive phytoconstituents. Boerhaavia diffusa Linn. (B. diffusa) commonly known as 'Punarnava or Rakhtpunarnava in ancient medicine system due to its regeneration properties in rainy season ${ }^{2,3}$ and classified as "rasayana" because of its therapeutic, chemical and ethanopharmacological values $^{4}$. It is reported that root of B.diffusa contains some vital alkaloids, ratenoids, lignans which are named as punarnavine, boeravinones A-F, liriodendrons, 
respectively. Flavonoids, amino acids, $\beta$-sitosterols and tetracosanoic, esacosanoic, stearic and ursolic acids were also reported, which has wide applicablity against chronic ailments ${ }^{4,5}$. The whole plant and its various parts were used in treatment of enlargement of spleen, cancer, jaundice, dyspepsia, inflammation, abdominal pain and also worked as an anti-stress, tonic and carminative agent ${ }^{6-10}$.

'Sarangdhar Samhita' has quoted the polyherbalism, which provide improved therapeutic efficacy by active than the individual plants. Multiple herbs composition in a fixed ratio gives better clinical results and reduce the toxic level ${ }^{11}$.

Phytochemical screening and isolation of marker compounds of this plant has confirmed the important bioactive chemicals (Boerhavin and boerhavic acid) including amino acids and alkaloids ${ }^{12-15}$. Boeravinones and other compounds in roots of $B$. diffusa were quantified and validated by analytical method like UPLC to enhance the quality and efficacy. This has been found selective and sensitive chromatographic method with good linearity, accuracy and precision ${ }^{22}$. Recently a rapid method was developed for quantitative estimation of Boeravinone-B in Punarnava. In such studies HPLC method was reported for determination of vitamins $C$ and $\mathrm{B}$ contents in B.diffusa and Commelina nudiflora leaves $^{18-20}$. The major constituents studied from the $B$. diffusa are punarnavine, boeravinone ${ }^{21}$, hypoxanthine 9-Larabinofuranoside, ursolic acid, punarnavoside, lirodendrin. The seeds have been studied as tonic and posses carminative properties ${ }^{22}$. Boerhadiffusene ,boerhavisterol, diffusarotenoid and boerhavilanostenyl benzoate and a known rotenoid, boeravinone A were identified from root part of $B$. diffusa $a^{26-28}$. Examination of the ether extracts of the roots of $B$. diffusa led to the separation of Boeravinone A, B, C, D, E, F, G and H by novel chromatographic method ${ }^{23-25}$.

Glycosides, flavonoids, tannins and saponins in the aqueous extract of leaves of $B$. diffusa exert hypoglycemic effect, were identified and assayed by means of standard TLC and HPTLC methods ${ }^{28}$. The same method was also used in isolation of Boeravinone-D, G and $H$. Likewise qualitative and quantitative analysis has also been reported through sophisticated and advance chromatographic technique ${ }^{29-30}$. UPLC was used for estimation of eight Boeravinones in methanolic extract of $B$. diffusa roots using PDA detector ${ }^{33}$.

The raw drug in market cannot be authenticated on the basis of their morphological or histological characteristics and poor quality drugs are less effective or it may worsen the clinical efficacy. So TLC method was also reported for adulteration analysis of $B$. diffusa with Trienthema portulacastrum Linn. in different Ayurvedic formulations, so it employed as an effective tool for quality control of market drugs ${ }^{31,32}$. Similarly HPLC, TLC, AAS and HNMR were used in fractions and extract of $T$. portulacastrum and $B$. diffusa to determine important bioactive compounds ${ }^{34}$ and it has been found chromatographic methods are simple, rapid and inexpensive in identification and comparison of Boeravinone ${ }^{38}$. Estimation of Boeravinone $B$ and Eupalitin-3-O- $\beta$-Dgalactopyranosid from whole plant of $B$. diffusa and single formulation (marketed Punarnava capsule) was carried out by HPLC method in concentration range $10-120 \mu \mathrm{g} \mathrm{mL}^{-1}$ and 5-60 $\mu \mathrm{g}$ $\mathrm{mL}^{-1}$ respectively ${ }^{35}$. In sequence of modern analytical methods various pharmacologically bioactive chemical compounds i.e., $\beta$-sitosterol, Boeravinone- $B$ and Eupalitin-3-o- $\beta$-d-galactopyranoside were isolated from methanolic extract of $B$. diffusa Linn., and from single drug formulations have also been reported.

Therefore after the literature review it may be concluded that $B$. diffusa has useful pharmacological activities to cure many ailments through its principal bio active chemical constituents like wise Boeravinone-B also has potent medicinal value. It also suggests that Ayurvedic formulations, ingredients and drugs of different pharmaceuticals may vary in quality, composition and properties due to lack of scientific practices and evidences. To produce effective clinical results there is need of uniform, rapid and precise analytical methods to establish the quality standards for safety and efficacy against drugs of poor quality and adulterants. Literature survey also revealed that such research work has not been published. Hence in this study an optimized RP-HPLC method tried for determination of Boeravinone-B qualitatively and quantitatively in hydro-alcoholic extract of $B$. diffusa whole plant and its processed poly-herbal formulation. It may be useful to set a quality parameter for the standardization of raw drug and various important pharmaceutical formulations of 
B. diffusa. The recommended method may be useful in cases of $B$. diffusa that are frequently adulterated with other species which are morphologically and chemically indistinguishable.

\section{Materials and Methods}

\subsection{Materials}

\subsubsection{Plant Materials (extract)}

The plant material in the form of powdered hydroalcoholic extract of $B$. diffusa (whole plant) was procured from an authentic supplier i.e., M/s Laila Impex (chemiloids), 40-15-14. Brindavan Colony, Labbipet Vijayawada 520010 authenticated vide voucher specimen LIH No. 6562.

\subsection{Chemicals and Reagents}

Boeravinone-B of $97.3 \%$ purity was procured from Natural Remedies Pvt. Ltd., Bangalore. HPLC grade acetonitrile and water of same grade were purchased from Rankem Ltd. for the study.

\subsubsection{Apparatus}

Chromatographic separation was performed on Agilent 1260 infinity high-performance liquid chromatography equipped with PDA detector and EZ Chrome Elite Software was employed for this study. Agilent Zorbax HC-C18 (2) $(250 \times 4.6 \mathrm{~mm}, 5 \mu$ particle size $)$ used as stationary phase.

\subsection{Methods}

\subsubsection{Preparation of Plant Material Samples}

\subsubsection{Preparation of Samples for HPLC Analysis}

\subsection{Batch-I and Batch-II, Ingredient (B. diffusa extract)}

Sample stock solution was prepared by taking about $250 \mathrm{mg}$ procured extract of batch I and II (mentioned in subheading 2.1.1) and dissolved in methanol in $10 \mathrm{~mL}$ standard flask. Volume was made up to the mark with HPLC grade methanol, sonicated for 10 min than filtered with $0.22 \mu$ filter to obtain its stock solutions of both batches.

\subsection{Poly-Herbal Formulation of Batch-I and Batch-II}

20 capsules (formulation composed of Boerhaavia diffusa, Emblica Officinalis, Tinospora cordifolia, Withania somnifera Glycyrrhiza glabra Bacopa monnieri, Centella asiatica) were taken, opened and crushed in mortar pestle. From that, weighed about $150 \mathrm{mg}$ powder for batch-I and $290 \mathrm{mg}$ powder for batch-II transferred to $10 \mathrm{~mL}$ volumetric flask separately. Make up the volume with methanol to prepare standard solution of both batches in standard flask, then applied to sonicated for 10 minutes.

\subsubsection{Preparation of Stock and Working Solution of Boeravinone-B for HPLC Analysis}

An accurately weighed quantity of Boeravinone-B $1.9 \mathrm{mg}$ was taken and dissolved in $2 \mathrm{~mL}$ methanol in standard flask. From the above stock solution, solution of different concentrations such as, 1.02, 2.02, 2.9 and $4.01 \mu \mathrm{g} / \mathrm{mL}$ of methanol were prepared.

\subsubsection{Experimental Section for HPLC}

The optimized parameters of HPLC method for the determination of Boeravinone- $\mathrm{B}$ are mentioned in the Table 1.

Table1. Chromatographic conditions for HPLC of Boeravinone-B.

Instrument HPLC - Agilent Technologies 1260 Infinity with PDA Detector

with EZ Chrome Elite Software

Stationary Phase Agilent Zorbax HC-

$\mathrm{C}_{18}$ (2) $(250 \times 4.6 \mathrm{~mm}$, particle size of $5 \mu)$

Wavelength $\quad 270 \mathrm{~nm}$

Run time $45 \mathrm{~min}$

Flow Rate $\quad 1.5 \mathrm{~mL} / \mathrm{min}$

Injection Volume $\quad 20 \mu \mathrm{L}$

Temperature $\quad 27^{\circ} \mathrm{C}$

Operation Mode Gradient elution

\subsubsection{Mobile Phase}

The mobile phase consisted of water/aqueous buffer and an organic modifier (miscible with water, acetonitrile was preferred for sharper peak). Based on sample solubility, stability and suitability various mobile phase compositions were tried. Mixtures of aqueous buffer 
and acetonitrile by gradient programming (Table 2.) with $0.1 \%$ acid was used as optimized mobile phases to separate the samples in desired components at $\mathrm{pH}$ 3.00 by $\mathrm{O}$-phosphoric acid was chosen with detection wavelength $270 \mathrm{~nm}$.

HPLC-type of reagents was used to minimize noise level. Freshly prepared mobile phase was used in this method to avoid the risk of contamination.

\section{a. Phosphate Buffer}

$0.140 \mathrm{~g}$ of anhydrous $\mathrm{KH}_{2} \mathrm{PO}_{4}$ dissolved in $900 \mathrm{ml}$ of HPLC grade Water \& then add $0.5 \mathrm{ml}$ of orthophosphoric acid and make up the volume with water to $1000 \mathrm{ml}$. Filtration of this solution was carried out by $0.45 \mu$ membrane filter and degassed in a sonicator for 3 minutes.

\section{b. Acetonitrile}

Table 2. Gradient programming

\begin{tabular}{|c|c|c|}
\hline Time & A Conc. (\%) & \\
\hline 0.01 & 95 & 0.5 \\
\hline 18.00 & 55 & 45 \\
\hline 25.00 & 20 & 80 \\
\hline 28.00 & 20 & 80 \\
\hline 35.00 & 55 & 45 \\
\hline 41.00 & 95 & 05 \\
\hline 45.01 & Stop & \\
\hline
\end{tabular}

\subsubsection{Validation of the Method}

The analytical method was validated for linearity (Table 3.) and system suitablility (Tabel 4),

Statistical calculations were carried out by Microsoft Excel 2007 of Windows software package to calculate Average, Sum, Standard Deviation (STDEV), Regression (RSQ) etc.

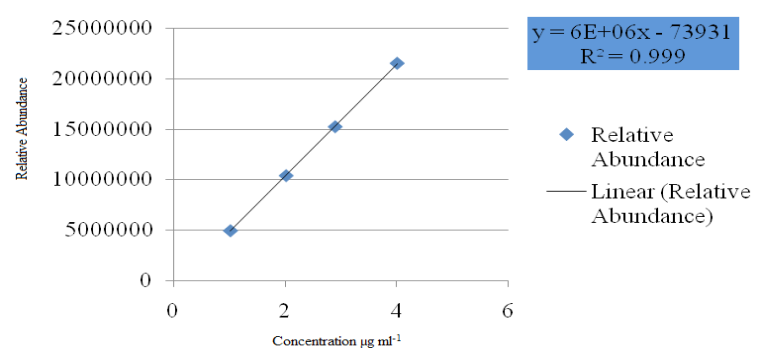

Figure 1. Linearity graph of Boeravinone-B for HPLC.

Tabel 4. System suitablility of Boeravinone-B

\begin{tabular}{|c|c|c|}
\hline S.No & RT & Area \\
\hline 1 & 24.413 & 21583716 \\
\hline 2 & 24.407 & 21604974 \\
\hline 3 & 24.413 & 21470020 \\
\hline 4 & 24.420 & 21482114 \\
\hline 5 & 24.413 & 21505072 \\
\hline 6 & 24.413 & 21474568 \\
\hline Average & 24.413 & 21520077.333 \\
\hline STD Deviation & 0.004 & 59161.702 \\
\hline \%RSD & 0.017 & 0.275 \\
\hline
\end{tabular}

Samples were scanned in UV 200-400 nm using PDA detector was performed to reveal eventual interfering compounds and evaluating the selectivity of the method. Specificity of this method was performed by comparing the HPLC retention time and absorption spectra of target peaks from the analyzed samples with that of the standard (marker).

Table 3. Linearity of Boeravinone-B

For assessing the linearity, the least square regression equation and correlation of coefficient were determined.

\begin{tabular}{|l|l|l|l|l|}
\hline \begin{tabular}{|l|l|l|} 
Concentration \\
$(\mu \mathrm{g} / \mathrm{mL})$
\end{tabular} & Peak Area & Slope & Intercept & $\mathbf{R}^{2}$ \\
\cline { 1 - 2 } 1.02 & 4946627 & 5525297.756 & 73931 & 0.999 \\
\cline { 1 - 2 } 2.02 & 10387124 & & & \\
\cline { 1 - 2 } 2.9 & 15211133 & & & \\
\hline 4.01 & 21474568 & & & \\
\hline
\end{tabular}




\section{Results and Discussion}

Chromatographic conditions were optimized after running different mobile phases concentrations based on sample solubility, stability \& polarity with a reversed phase $\mathrm{C} 18$ column on hit and trial basis. A good resolution and sharp peaks of Boeravinone- $B$ in standard, ingredient and poly-herbal formulation were obtained in gradient system in the mixture of phosphate buffer and acetonitrile. The content of Boeravinone- $B$ in formulation and ingredient of $B$. diffusa was analyzed using optimized chromatographic method. Detection wavelength selected as $270 \mathrm{~nm}$ in an acceptable response and used for estimation of marker compound in this study. Column temperature was maintained at $27^{\circ} \mathrm{C}$ throughout analysis. The standards of different strengths, extracts of plant material and poly-herbal formulation were injected in the RP-HPLC column and obtained peak areas of Boeravinone-B were used for analysis of content by the regression equation. Well resolved sharp peak of Boeravinone-B obtained at Rt $24.413 \pm 0.004$ identified in standard (Figure 2), hydro-alcoholic extract of B.diffusa of Batch-I and II

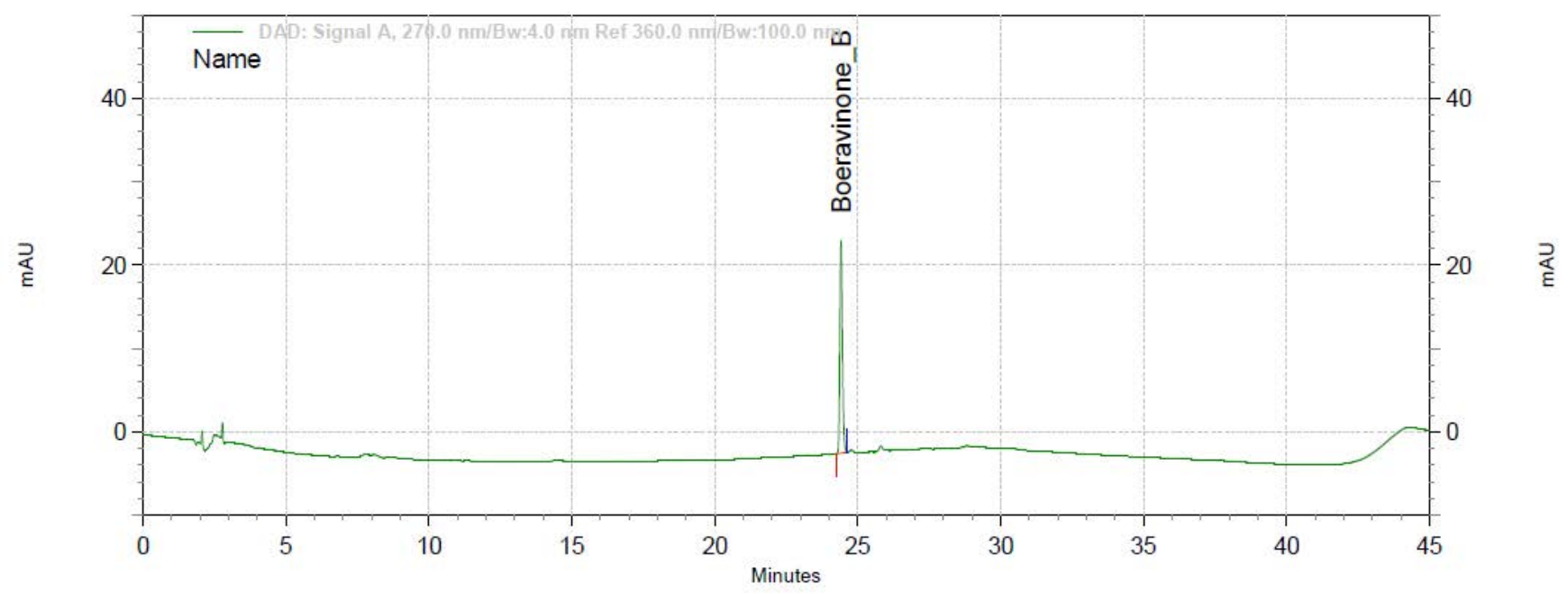

Figure 2. Chromatogram of Boeravinone-B standard $4.01 \mu \mathrm{g} / \mathrm{mL}$.

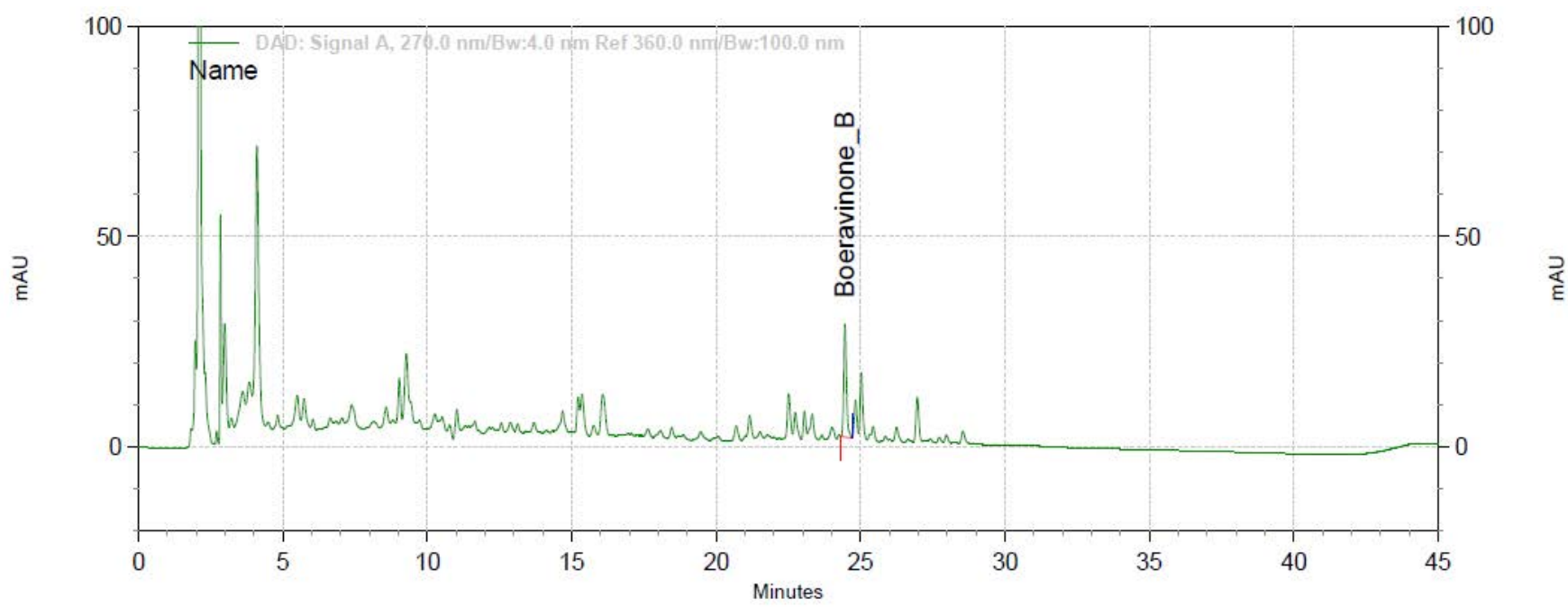

Figure 3. Chromatogram of hydro-alcoholic extract of B.diffusa: Batch-I. 


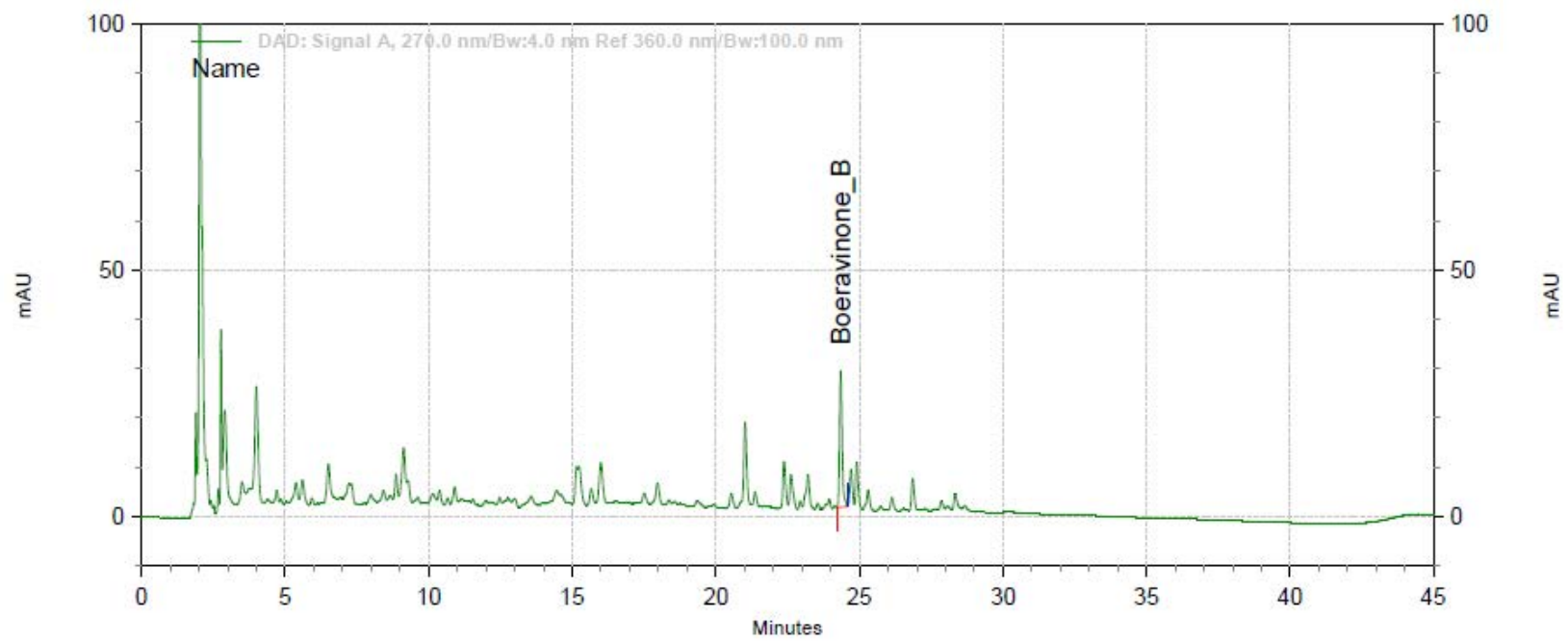

Figure 4. Chromatogram of hydro-alcoholic extract from B. diffusa: Batch-II.

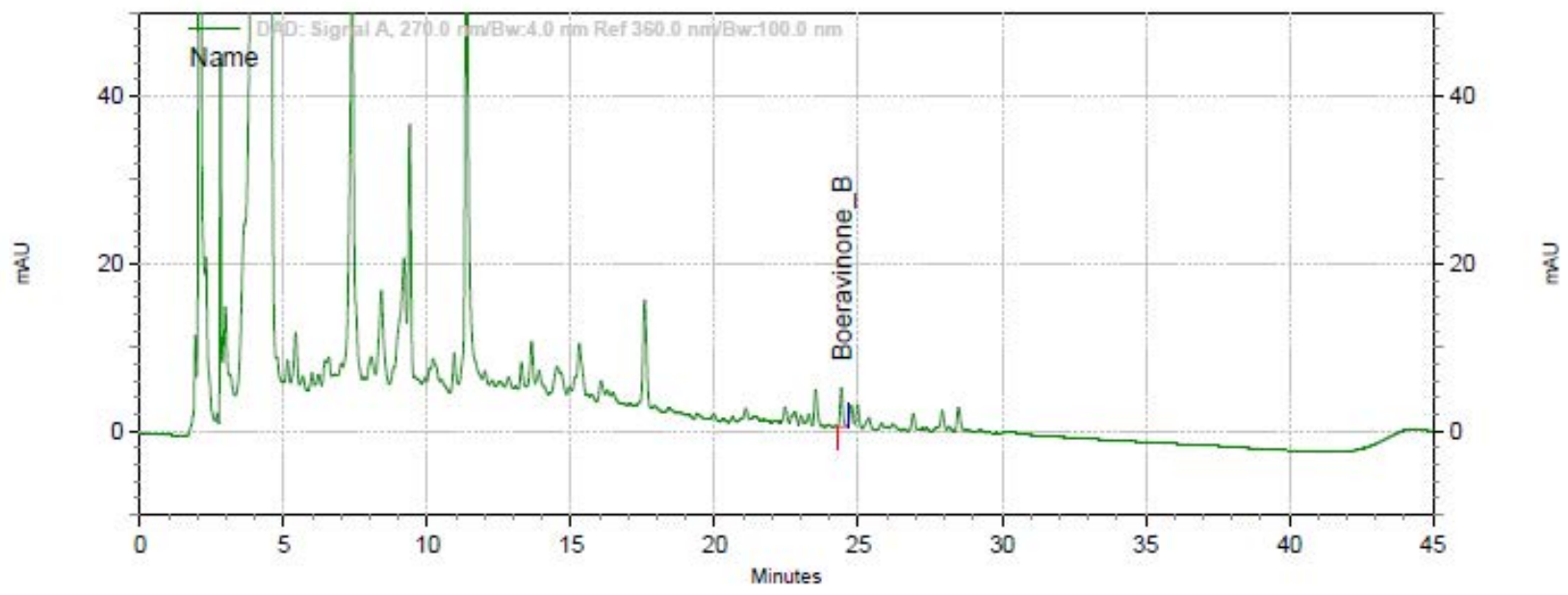

Figure 5. Chromatogram of poly-herbal formulation: Batch-I.

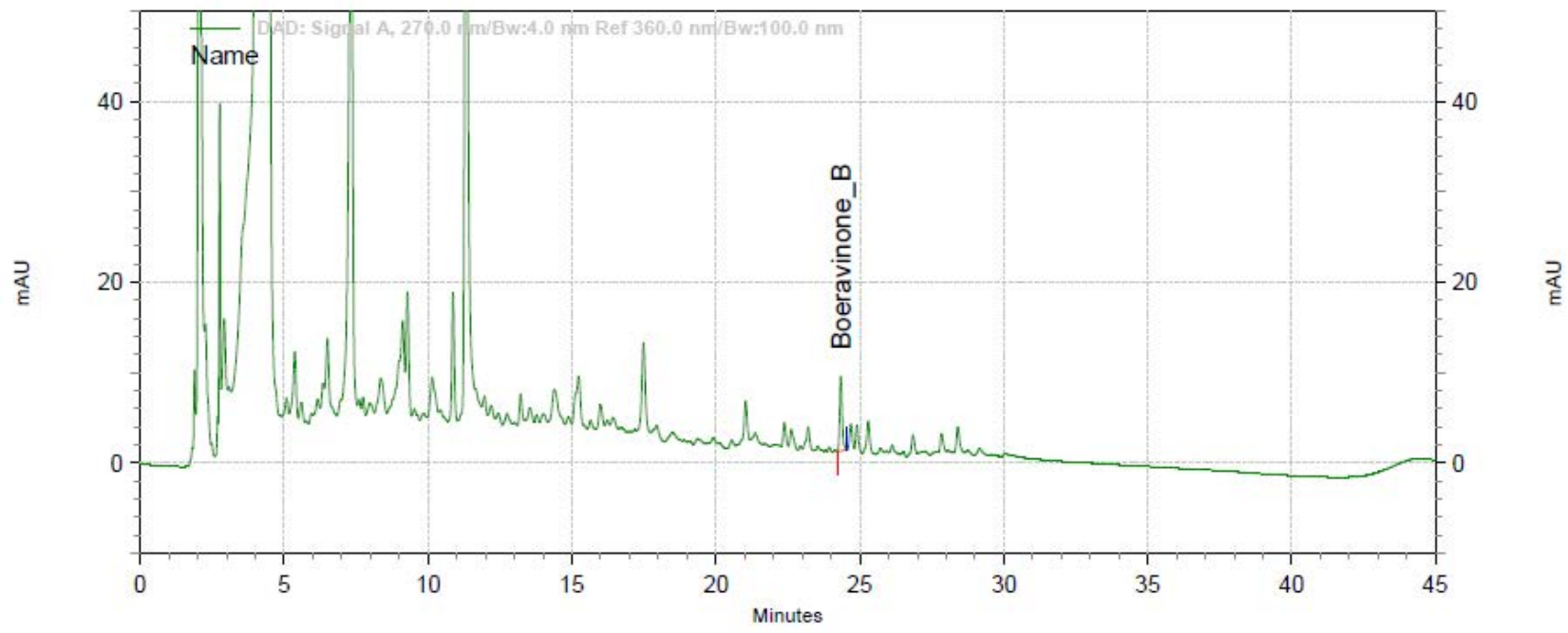

Figure 6. Chromatogram of poly-herbal formulation: Batch-II. 
(Figure 3-4) and poly-herbal formulation of batch-I and II (Figure 5, 6).

The graphical study of Figure 3-6 has revealed that peak height in terms of concentration of Boeravinone- $B$ is more in ingredients than formulations. Percentage of Boeravinone B in ingredients (hydro-alcoholic extracts) and poly-herbal formulation was calculated to be $0.041 \% \mathrm{w} / \mathrm{w}$ and $0.011 \% \mathrm{w} / \mathrm{w}$ respectively, this validates the composition ratio of ingredient in formulation i.e., less in formulation than ingredient. It complies with the API limit and reassures the fact that almost one fourth of the formulation consists of $B$. diffusa. This signifies precision of present study and suggested that ingredient of poly-herbal formulation predominately contains Boeravinone-B in a perfect ratio. Such research study may be recommended for quality control in various pharmaceuticals to make a uniform approach in clinical research. HPLC chromatograms may also help to evaluate the adulterants and identification of standard and pure raw material.

\section{Conclusions}

Results of this study have revealed that Boeravinone- $B$ is present in ingredient (B. diffusa extract) and poly-herbal formulation i.e. $0.041 \% \mathrm{w} / \mathrm{w}$ and $0.011 \% \mathrm{w} / \mathrm{w}$ respectively which scientifically validate the ratio of ingredient in finished drug. It may become a versatile method for qualitative (identity) and quantitative analysis in quality control of various market formulations containing $B$. diffusa to enhance their efficacy. The results of analysis comply with several Quality standards books/official pharmacopoeias ${ }^{16,17,36}$. It presents a very good resolution with greater sensitivity and linearity associated with the coulometric detector than the other conventional methods ${ }^{28}$. This study may widen the acceptability criteria of ayurvedic drugs containing B.diffusa globally through estimation of marker(Boeravinone-B) in raw material, intermediate as well as various finished phytoformulations.

\section{Conflict of Interests}

No competing financial interests exist.

\section{Acknowledgements}

The authors would like to express special thanks to the Director General, Central Council for Research in Ayurvedic Sciences, New Delhi for providing the desired facilities and support to carry out this work.

\section{References}

1. Chauhan A, Semwal DK, Mishra SP, Semwal RB. Ayurvedic research and methodology: Present status and future strategies. AYU. 2015 Oct-Dec; 36(4):364-9. https://doi. org/10.4103/0974-8520.190699 PMid:27833362 PMCid : PMC5041382

2. Lad V. The complete book of ayurvedic home remedies. New York: Three Rivers Press; 1999.

3. Chopra GL. Angiosperms. systematic and life cycle. Jalandhar, Punjab, India: S. Nagin and Co; 1969. p. 361-5.

4. Mishra S, Aeri V, Gaur PV, Jachak SM. Phytochemical, therapeutic, and ethnopharmacological overview for a traditionally important herb: Boerhavia diffusa Linn. Hindawi Publishing Corporation BioMed Research International; 2014. Article ID 808302:1-19.

5. Wahi AK, Agrawal VK, Gupta RC. Phytochemical and pharmacological studies on Boerhaavia diffusa Linn (punarnava) alkaloids. National Academy of Science Letters. 1997; 20.

6. Kirtikar KR, Basu BD. Boerhaavia diffusa. Indian Medicinal Plants. Allahabad, India: Lalit Mohan Basu Publications; 1956. p. 2045-8.

7. Chakraborti KK, Handa SS. Antihepatotoxic activity of Boerhaavia diffusa. Indian Drugs. 1989; 27(13):161-6.

8. Aslam M. Asian medicine and its practice in Britain. In: Evans WC, editor. Pharmacognosy. London UK: Saunders Company Ltd; 1996. p. 499-500.

9. Rawat AK, Mehrotra S, Tripathi SC, Shome U. Hepatoprotective activity of Boerhaavia diffusa L. roots-a popular Indian ethnomedicin. Journal of Ethnopharmacology. 1997; 56(1):61-6. https://doi. org/10.1016/S0378-8741(96)01507-3

10. Garg S. Proteins and free amino acid composition of certain Indian desert plants. I. Transactions of the Indian Society Desert Technology, University of Desert Studies. 1978; 3(1):31-4.

11. Subramani P, Gan ST, Sokkalingam AD. Polyherbal formulation: Concept of ayurveda. Pharmacognosy 
Identification and Quantification of Boeravinone-B in Whole Plant Extract of Boerhaavia diffusa Linn and in its Polyherbal Formulation

Review. 2014; 8(16):73-80. https://doi.org/10.4103/09737847.134229 PMid:25125878 PMCid:PMC4127824

12. Lami N, Kadota S, Kikuchi T, Momose Y. Constituents of the roots of Boerhaavia diffusa L. III. Identification of a Ca channel antagonistic compound from the methanol extract. Chemical and Pharmacological Bulletin. 1991; 39(6):1551-5. https://doi.org/10.1248/cpb.39.1551

13. Liogier A. Plantas medicinales de puerto rico ydel caribe. Iberoamerican de Ediciones Inc. San Juan. 1990; 123-7.

14. Szepesi GJ. Planar Chromatogr. Mod TLC. 1993; 6:187.

15. USP, Validation of Compendial Methods 1225. The Pharmacopoeia of the United States of America, Rockville, MD: United States Pharmacopoeial Convention Inc; 2002. p. 2256-9.

16. Agrawal B, Das S, Pandey A. Boerhaavia diffusa Linn.: A review on its phytochemical and pharmacological profile. Asian Journal of Applied Sciences. 2011; 4(7):663-84. https://doi.org/10.3923/ajaps.2011.663.684

17. Indian Pharmacopoeia. Indian Pharmacopoeia Committee. New Delhi: Ministry of Health and Family Welfare, Government of India; 2007. p. 1423-4.

18. Ayurvedic Pharmacopoeia of India. Dept of AYUSH. New Delhi: Ministry of Health and Family Welfare, Government of India; 1990. p. 126-8.

19. Miralles J, Noba K, Ba AT, Gaydou EM, Kornprobst JM. Chemotaxonomy in Nyctagynaceae family: sterols and fatty acids from the leaves of three Boerhaavia species. Biochemical Systematics and Ecology. 1988; 16(5):475-8. https://doi.org/10.1016/0305-1978(88)90047-6

20. Bairwa K, Srivastava A, Jachak SM. Quantitative analysis of Boeravinone-B in the roots of Boerhaavia diffusa by UPLC/PDA. Phytochemical Analysis. 2014. https://doi. org/10.1002/pca.2509 PMid:24677242

21. Christian M. Flavonoids-chemical constituents of Boerhaavia diffusa 1 . through TLC and HPTLC. International Research Journal of Chemistry. 27-36.

22. Nayak P, Thirunavoukkarasu M. A review of the plant Boerhaavia diffusa: Its chemistry, pharmacology and therapeutical potential. The Journal of Phytopharmacology. 2016; 5(2):83-92.

23. Aslam M. Asian medicine and its practice in Britain. In: Evans WC, editor. Pharmacognosy. Saunders Company Ltd, London UK.1996; 499-500.

24. Gupta J, Ali M. Chemical constituents of Boerhaavia diffusa Linn. Roots. Ind J Chem. 1998; 37:912-7.

25. Kadota S, Lami N, Tezuka Y, Kikuchi T. Constituents of the roots of Boerhaavia diffusa Linn. I. Examination of sterols and structures of new rotenoids (boeravinones A and
B).Chemical Pharmaceutical Bullet.1989; 37(12):3214-20. https://doi.org/10.1248/cpb.37.3214

26. Lami N, Kadota S, Tezuka Y, Kikuchi T. Constituents of the roots of Boerhaavia diffusa Linn. II. Structure and stereochemistry of a new rotenoid boeravinone C2. Chemical Pharmaceutical Bullet.1990; 38(6):1558-62. https://doi.org/10.1248/cpb.38.1558

27. Lami N, Kadota S, Kikuchi T, Momose Y. Constituents of the roots of Boerhaavia diffusa L. III. Identification of a $\mathrm{Ca}+2$ channel antagonistic compound from the methanol extract. Chemical Pharmaceutical Bullet. 1991; 39(6):1551-5. https://doi.org/10.1248/cpb.39.1551

28. Shukla A, Gupta RK. Effect of the aqueous extract of Boerhavia Difusa roots and leaves of hypoglycemic as well as immuno support activity. International Research Journal of Biological Sciences. 2012; 1(6):62-5.

29. Aviello G, Canadanovic-Brunet JM, Milic N, Capasso R, Fattorusso E, Taglialatela-Scafati O. Potent antioxidant and genoprotective effects of Boeravinone G, a rotenoid isolated from Boerhaavia diffusa. PLoS ONE.2011; 6(5). https://doi.org/10.1371/journal.pone.0019628 PMid:21625488 PMCid:PMC3098844

30. Lal VKP, Verma A. HPTLC densitogram profile of aqueous distillate (Arka) from roots of Boerhaavia diffusa. BJPR. 2016; 9(1):1-6. https://doi.org/10.9734/BJPR/2016/19399

31. Vijayakrishna AC, Shreedhra CS, Latha KP, Belvotagi AV. Thin layer chromatography as a tool for quality control of punarnava. J of Pharmaceutical and Scientific Innovation. 2014 Jul-Aug; 3(4):375-8. https://doi.org/10.7897/22774572.034177

32. Baralcat HH, Sahar Hussin AM, Mohamed Marzouk S, Merfort I, Linscheid M, Nawwar Mohamed AM. Polyphenolic metabolities of Epilobium hirsutisam. Phytochemistry. 1997; 46:935-41. https://doi.org/10.1016/ S0031-9422(97)00370-1

33. Bairwa K, Srivastava A, Jachak SM. Phytochem Anal. 2014 Sep-Oct; 25(5):415-20. https://doi.org/10.1002/pca.2509 PMid:24677242

34. Aldon G, Vikas VV, Ravikiran DB, Jaydeep G. Seapration and questification of pharmacologically active markers boeravinone B, eupalitin-3-o- $\beta$-sitosterol from Boerhavia diffusa Linn and from marketed formulations. International Journal of Pharmacy and Pharmaceutical Sciences. 2013; 5(3).

35. Vaidya VV, Gomes A, Gadgil J, Patil S. HPLC analysis of Boeravinone B and eupalitin-3-o- $\beta$-d-galactopyranoside from plant and formulation of Boerhavia diffusa linn. IJRPC. 2014; 4(4):982-6.

36. Quality Standards of Indian Medicinal Plants. New Delhi: Indian Council of Medical Research; 2011. p. 59-71. 